\title{
MONITORING PHARMACEUTICALS AND PERSONAL CARE PRODUCTS IN RESERVOIR WATER USED FOR DRINKING WATER SUPPLY
}

\author{
Carolina Aristizabal-Ciro ${ }^{\mathrm{a} *}$, Ana María Botero-Coy*b, Francisco J. López ${ }^{\mathrm{b}}$, Gustavo A. Peñuela ${ }^{\mathrm{a}}$
}

${ }^{a}$ Grupo GDCON, Facultad de Ingeniería, Sede de Investigación Universitaria (SIU), Universidad de Antioquia, Calle 70 No 52-21, Medellín, Colombia

${ }^{b}$ Research Institute for Pesticides and Water, University Jaume I, Avda. Sos Baynat, E-12071 Castellón, Spain.

* Authors for correspondence. Both authors contributed equally to the design, development, writing and revision of the present article

Carolina Aristizabal (carolina.aristizabalc@udea.edu.co, Tel: +57 4 2196571)

Grupo GDCON, Facultad de Ingeniería, Sede de Investigación Universitaria (SIU)

Universidad de Antioquia, Calle 70 No 52-21

Medellín, Colombia

Ana María Botero-Coy (botero@uji.es, Tel: +34 964 387391)

Research Institute for Pesticides and Water

University Jaume I, Castellón, Spain 
In this work, the presence of selected emerging contaminants has been investigated in two reservoirs, La $\mathrm{Fe}$ (LF) and Riogrande (RG), which supply water to two drinking water treatment plants (DWTPs) of Medellin, one of the most populated cities of Colombia. An analytical method based on solid phase extraction (SPE) of the sample followed by measurement by liquid chromatography coupled to tandem mass spectrometry (LC-MS/MS) was developed and validated for this purpose. Five monitoring campaigns were performed in each reservoir, collecting samples from 7 sites (LF) and 10 sites (RG) at three different depths of the water column. In addition, water samples entering in the DWTPs and treated water samples from these plans were also analyzed for the selected compounds. Data from this work showed that parabens, UV filters and the pharmaceutical ibuprofen were commonly present in most of the reservoir samples. Thus, methyl paraben was detected in around $90 \%$ of the samples collected, while ibuprofen was found in around $60 \%$ of the samples. Water samples feeding the DWTPs also contained these two compounds, as well as benzophenone at low concentrations, which was in general agreement with the results from the reservoir samples. After treatment in the DWTPs these three compounds were still present in the samples although at low concentrations $(<40 \mathrm{ng} / \mathrm{L})$, which evidenced that they were not completely removed after the conventional treatment applied. The potential effects of the presence of these compounds at the ppt levels in drinking water are still unknown. Further research is needed to evaluate the effect of chronic exposure to these compounds via consumption of drinking water. 
Reservoirs are artificial lakes formed by the accumulation of water from rivers, creeks, streams and other natural sources, which are subject to the influence of its tributaries and associated watersheds. Storage in a reservoir increases the availability of water for various purposes, such as the generation of electric power, irrigation of crops, industrial use and supply of drinking water for human consumption, among others (Martinez-Zapata, 2011). Specifically, the quality of drinking water is conditioned by the water of the reservoirs that feed the treatment plants producing drinking water. These systems are exposed to numerous natural and anthropogenic factors (Uhlmann et al., 2011). The impact of human activities on the aquatic environment has increased due to the growth in population and industrialization, which has intensified discharges from domestic, industrial and agricultural wastewater, the main sources of pollution.

Nowadays, there is a general concern on the presence of emerging contaminants in the water environment. Pharmaceuticals and personal care products (PPCPs) are of particular concern due to their wide use and their occurrence in treated wastewater and surface waters (Gracia-Lor et al., 2012a, 2012b). These compounds are not regulated yet in water legislation and can be harmful for the aquatic ecosystem, and become a hazard for human public health (Barceló and Petrovic, 2007; Daughton, 2004; Farré et al., 2008). These compounds are present in urban wastewater, but are not efficiently removed in the wastewater treatment plants (WWTP) that apply conventional treatments (Gracia-Lor et al., 2012b; Gros et al., 2010; Jelic et al., 2011; Lacey et al., 2008). In addition to the inefficient removal in WWTPs, some of them are also persistent and can be bioaccumulated in living organisms (Daughton and Ternes, 1999; Yang et al., 2014; Zeng, 2015). Within the group of PPCPs, many different families of compounds can be included, as those used in medicine, veterinary or agriculture, cosmetics, UV filters, fragrances, and even additives in food (Farré et al., 2008; Martinez Bueno et al., 2016). Oppositely to most priority pollutants included in the current legislation, which have high toxicity and/or persistence in the environment, PPCPs do not commonly have these characteristics, but are continuously released in the aquatic ecosystems (via urban wastewater), where non short-term detectable effects may occur (Muñoz et al., 2008), although long-term effects are still unknown. The fact that many PPCPs are not efficiently removed in the WWTPs means that these compounds can easily reach surface water (Dai et al., 2015; Kasprzyk-Hordern et al., 2008; Liu et al., 2015; Matamoros et al., 2012) and even drinking water (Boyd et al., 2003; Carmona et al., 2014; Kumar and Xagoraraki, 2010; Sodré et al., 2010; Vulliet et al., 2011). Colombia has many aquatic ecosystems providing water for human and industrial consumption. Specifically, Antioquia province is very rich in hydric resources, which are used for energy and drinking water production. This is the case of the reservoirs La Fe (LF) and Riogrande (RG), which are the source of water supply of the two drinking water treatments plants (DWTPs) of Medellin: La Ayurá (LA) and Manantiales (MA). Although these reservoirs are located in low population areas, they can receive the impact of wastewater, both from urban and agricultural origin (Martinez and Peñuela, 2013). Therefore, it becomes necessary to investigate the occurrence of emerging contaminants to have a better knowledge on the presence of these compounds in the reservoirs, and eventually in drinking water. 
The objective of this work was to investigate the presence of selected PPCPs in water samples from these two reservoirs, and in samples entering in two DWTPs that use water from these reservoirs, as well as in treated drinking water samples. To this aim, an analytical method based on the use of liquid chromatography coupled to tandem mass spectrometry (LC-MS/MS) was developed and validated for the determination of ibuprofen (IBU), diclofenac (DIC), clofibric acid (ACF), carbamazepin (CBZ), benzophenone (BZP), benzophenone-3 (BZP-3), methylparaben (MePB), ethylparaben (EtPB) and buthylparaben (BuPB) in surface water. A solid phase extraction (SPE) was applied to water samples, which allowed to obtain a pre-concentration factor of 200. Five monitoring campaigns were performed in each reservoir, collecting waters from seven sites (LF reservoir) and 10 sites (RG reservoir) at three different water column depths: sub-surface, photic zone limit, and bottom. In addition, samples from the entrance and the exit of the DWTPs were also analysed for these compounds. Considering the general lack of data on PPCPs in Colombian surface waters, particularly in the Medellin area, this paper was conceived as a preliminary study to investigate the presence of some of the most consumed/used compounds in the area under study. Further studies will be required, including more PPCPs and metabolites/transformation products (TPs), to have a better knowledge of the issue treated, and to suggest subsequent actions to protect the aquatic environment, if needed.

\section{Experimental}

\subsection{Regents and chemicals}

Reference standards of ibuprofen (99\%), diclofenac (99\%), clofibric acid (99.5\%), and carbamazepin (99.5\%) were from Dr. Ehrenstorfer (Germany); benzophenone (99.4\%), methylparaben (99.5\%), ethylparaben (99.5\%) and buthylparaben (99.5\%) from Chemservice (West Chester, USA); and benzophenone-3 (100\%) from Accustandard (New Haven, USA). Isotope-labelled internal standards (ILIS) of ibuprofen-d3 (IBU-d3) was from Toronto Research Chemicals TRC (Toronto-Ontario, Canada), and ethylparaben- $\mathrm{d}_{4}$ (EtPB-d4) from CDN Isotopes (Quebec, Canada). LC-MS grade methanol was from Merck (New Jersey, USA) and acetonitrile from Honeywell, B. \& J. Brand (USA). HPLC-grade water was obtained by purifying demineralized water in a Milli-Q Gradient A10 (Millipore, Bedford, MA, USA). Formic acid 98-100\% was from Merck (New Jersey, USA).

Individual stock solutions of $1000 \mathrm{mg} / \mathrm{L}$ of both, reference standards and ILIS, were prepared by dissolving $10 \mathrm{mg}$ in $10 \mathrm{ml} \mathrm{MeOH}$. From these individual solutions, a mix solution of $100 \mathrm{mg} / \mathrm{L}$ containing the PPCPs was prepared by dilution in $\mathrm{MeOH}$. Working mix solutions of 10,1 and $0.1 \mathrm{mg} / \mathrm{L}$ PPCPs were prepared in $\mathrm{MeOH}$ from the $100 \mathrm{mg} / \mathrm{L}$ mix solution. A mix solution of ILIS of $2 \mathrm{mg} / \mathrm{L}$ IBU-d3 and 10 $\mathrm{mg} / \mathrm{L}$ EtPB-d4 was also prepared in MEOH from a $100 \mathrm{mg} / \mathrm{L}$ solution.

Sample extraction was made by solid phase extraction (SPE) using Oasis HLB cartridges (60 mg) from Waters Corp. (Milford, MA, USA).

\subsection{Liquid chromatography}


An Acquity UPLC system (Waters Corp., Milford, MA, USA) was used, equipped with a quaternary solvent manager and a sample manager. Chromatographic separation was performed using an Acquity UPLC BEH C18 column, $2.1 \times 50 \mathrm{~mm}, 1.7 \mu \mathrm{m}$, (Waters) at a flow rate of $0.3 \mathrm{~mL} / \mathrm{min}$. The column was kept at $40^{\circ} \mathrm{C}$ and the sample manager was maintained at $5{ }^{\circ} \mathrm{C}$. The mobile phase consisted of water with a $0.01 \% \mathrm{HCOOH} /$ methanol gradient. The methanol percentage was changed linearly as follows: $0 \mathrm{~min}$, 10\%; $9 \mathrm{~min}, 90 \%$; $9.5 \mathrm{~min}, 90 \%$; $10.5 \mathrm{~min}, 100 \%$; $10.6 \mathrm{~min}, 100 \%$; $11.7 \mathrm{~min}, 10 \%$. Analysis run time was $12.7 \mathrm{~min}$. The sample extract injection was $20 \mu \mathrm{L}$.

\subsection{Mass Spectrometry}

An Acquity UPLC system was coupled to a TQD (triple quadrupole) mass spectrometer with an orthogonal Z-spray-electrospray (ESI) (Waters Corp., Milford, MA, USA). Both the drying gas and the nebulising gas was nitrogen generated from pressurized air in a $\mathrm{N}_{2}$ LC-MS nitrogen generator (Peak Scientific, EE. UU). The cone gas and the desolvation gas flows were set at 80 and $800 \mathrm{~L} / \mathrm{h}$, respectively. For operation in MS/MS mode, the collision gas was Argon $99.995 \%$ at $2 \times 10^{-3}$ mbar in a T-Wave collision cell. Capillary voltages of $-2.8 \mathrm{kV}$ (negative ionization mode) and $3.0 \mathrm{kV}$ (positive ionization mode) were applied. The interface temperature was set to $450{ }^{\circ} \mathrm{C}$ and the source temperature to $150{ }^{\circ} \mathrm{C}$. Dwell times of $0.1 \mathrm{~s}$ were selected. Masslynx 4.1 (Micromass, Manchester, UK) software was used to process the quantitative data.

The studied compounds were measured in ESI positive and/or ESI negative mode during the same injection acquiring two MS/MS transitions per compound. The acquisition of two transitions, of which the most sensitive was used for quantification (Q) and the other was used for confirmation (q), ensured the appropriate identification of the analytes in the samples. Only one transition was available for IBU $205>161$ (Q) due to the poor fragmentation of this compound under the conditions applied. The transitions selected, and the optimized conditions of cone voltage and collision energy are shown in Table 1.

\subsection{Sample procedure}

Water samples were firstly centrifuged (Boeco Centrifuge U-320R, Germany) for $10 \mathrm{~min}$ at $4500 \mathrm{rpm}$ to separate particulate matter (filtration was discarded to avoid potential losses in the filter). Then, SPE was applied within $48 \mathrm{~h}$ after samples collection. When this was not possible, the centrifuged samples were stored in the freezer at $-20^{\circ} \mathrm{C}$ (Revco-Thermo Scientific). Conditioning of the SPE cartridges was made with $3 \mathrm{~mL} \mathrm{MeOH}$ and $3 \mathrm{~mL}$ ultrapure water. After conditioning, $200 \mathrm{~mL}$ of the water sample (adding 50 $\mu \mathrm{L}$ of the mix ILIS solution ( $2 \mathrm{mg} / \mathrm{L} \mathrm{IBU}-\mathrm{d} 3,10 \mathrm{mg} / \mathrm{L}$ EtPB-d4) ) were loaded into the SPE cartridge at a flow of 1-2 $\mathrm{mL} / \mathrm{min}$. The cartridges were air dried, and analytes were eluted with $5 \mathrm{~mL} \mathrm{MeOH}$. The eluate was evaporated under a gentle nitrogen stream and the residue was reconstituted $1 \mathrm{~mL}$ MeOH-H2O $(10: 90, v / v)$. Finally, $20 \mu \mathrm{L}$ of the extract was injected into the UHPLC-MS/MS system under conditions indicated in Table 1. 
Quantification was made with standards prepared in solvent, using relative responses analyte/ILIS, or absolute responses, depending on whether ILIS was used for correction or not. All compounds measured in negative mode were quantified using ILIS for matrix effects correction. Thus, parabens (MePB, EtPB and $\mathrm{BuPB}$ ) were quantified using EtPB- $\mathrm{d}_{4}$, while IBU was quantified using IBU- $\mathrm{d}_{3}$. After a previous study on the best ILIS to be used for matrix effects correction, EtPB-d4 was selected for quantification of DIC and ACF. The three compounds measured in positive mode (CBZ, BZP, BZP-3) were quantified by external calibration using standards in solvent without ILIS due to the unavailability of appropriate ILIS in our laboratory. In any case, our data did not show relevant matrix effects for these compounds in the samples tested.

\subsection{Study Area and samples collection}

The present study was carried out in two reservoirs (RG and LF) that are used for drinking water supply to the city of Medellin after the water being treated in two DWTPs. Samples were taken from three depths: the subsurface, photic zone limit and reservoir bottom in order to evaluate the presence of pollutants along the overall water column. Ten sampling locations were selected in reservoir RG (Fig 1) and seven locations in reservoir LF (Fig 2). Additionally, water samples were also collected in each tributary at locations before the entry to the each reservoir (Figure 1, numbers 12, 15, 17 and 19; Figure 2, numbers 8, 9, 10 and 11). The samples were collected using a Schindler bottle. An aliquot of $200 \mathrm{~mL}$ of each sample was transferred to amber glass bottles that were previously cleaned and heated to $450{ }^{\circ} \mathrm{C}$ for $8 \mathrm{~h}$ to remove any presence of organic matter. Then, they were transported to the laboratory under cooled conditions $\left(4^{\circ} \mathrm{C}\right)$.

Influent and effluent samples from the two DWTPs (Manantiales (MA), fed with water from reservoir RG; and La Ayurá (LA) fed with water from reservoir LF) consisted on 24-h composite samples. The effluent samples (i.e. drinking water supplied to Medellin) were amended with sodium thiosulfate immediately after collection to eliminate residual chlorine (Martinez and Peñuela, 2013).

The monitoring plan for reservoirs, tributary rivers and DWTPs is summarised in Table 1SI (Supplementary Information).

\section{Results and discussion}

The selection of the compounds under study was made based on the main human activities in the area and on previous data reported in a preliminary study performed on the presence of PPCPs (Gracia-Lor et al., 2012a). The area around reservoir LF and their tributaries has experimented an increased urbanization process and recreational events, including the touristic park Los Salados. Reservoir RG is more affected by agricultural activities, and several farms (mainly cattle and pigs) are located in the nearby areas. Despite the presumably presence of pesticides, because of the agricultural activities, we focused our study on pharmaceuticals. Thus, four compounds were selected such as ibuprofen and diclofenac, which are analgesic/anti-inflammatory drugs commonly consumed around the world (Mendez-Arriaga et al., 2010; Scheurell et al., 2009) and specifically in Colombia; they are easily accessible for consumers and are 
included in the Colombian national strategy for Human Health. Carbamazepine is used for epilepsy treatment and is frequently found in natural and waste waters (Bade et al., 2015; Hernández et al., 2015; Sun et al., 2013); and clofibric acid, which is used to decrease cholesterol and triglicerids levels in blood (Saravanan et al., 2011).

A preliminary study made by our own group in collaboration with the University Jaume I of Castellon (Gracia-Lor et al., 2012a) revealed the presence of several personal care products in waters from these two reservoirs, specifically benzophenones, commonly used in UV filters and other products of wide use. Benzophenone and benzophenone-3 were identified in several of the samples. Parabens, used as preservatives in cosmetics and even as additives in food, were also found in the water samples (methyl paraben, ethyl paraben, and buthyl paraben).

Altogether, 9 PPCPs were selected for this study, 4 of them being drugs of wide consumption and/or frequent detection in waters, and 5 being personal care products.

\subsection{Analytical Methodology}

The method linearity was studied in the range 1-100 $\mu \mathrm{g} / \mathrm{L}$. Calibration curves showed satisfactory correlation coefficients (greater than 0.99 ) and residuals were lower than $30 \%$. The method accuracy was evaluated in surface water spiked $(\mathrm{n}=5)$ at three concentration levels $(0.05,0.25$ and $0.45 \mu \mathrm{g} / \mathrm{L})$. The results were satisfactory in terms of precision, expressed as relative standard deviation (RSD) (lower than $20 \%$ ) and accuracy, expressed as percentage recovery (between 70 and $120 \%$ ) for the analysis of PPCPs under study (Table 2).

Limits of detection (LOD) were calculated as a function of the standard deviation for a $99 \%$ confidence level (Brown and Berthouex, 2002; Martinez-Zapata, 2011), $(\mathrm{n}=7)$ in a sample spiked at $0.25 \mu \mathrm{g} / \mathrm{L}$. Limits of quantification (LOQ) were taken as $3.3 \times$ LOD (Table 2).

Confirmation of positive findings was carried out by calculating the peak area ratios between the quantification $(\mathrm{Q})$ and confirmation (q) transition. The finding was considered as true positive when the experimental ion-ratio was within the tolerance range (Gracia-Lor et al., 2012b), and the retention time in the sample within $\pm 2.5 \%$ when compared with a reference standard (see Table 1 for Q/q ratios empirically obtained for reference standards).

A problem occurred in the determination of BZP, which seemed to be related to a contamination of the LC-MS/MS system used for analyses. For this reason, data were available only for samples collected until October 2012. From then on, although a peak clearly differentiated from the blank was observed for several of the samples (suggesting that the sample was positive for this compound), we could not accurately quantified this analyte.

\subsection{Reservoir samples}

The validated method was applied to water samples collected from reservoirs and the drinking water treatment plants. In every sequence of analysis (around 20 samples), a calibration curve was injected. 
Quality control (QC) samples (i.e blank samples fortified at $0.25 \mu \mathrm{g} / \mathrm{L}$ with the selected PPCPs) were also analyzed in every sequence in order to test the robustness and applicability of the method to the samples under study. Confirmation of positive findings was based on the agreement of $\mathrm{Q} / \mathrm{q}$ ratios and chromatographic retention times between samples and reference standards (see Analytical Methodology).

\subsubsection{Reservoir Rio Grande (RG)}

The highest percentage of positive samples corresponded to BZP, MePB and IBU, which were detected in many of the samples analysed (Table 3). In relation to DIC, it was only found in the samples from April (11\% positives) and November (3\% positives), always at levels below LOQ. BZP-3 was only detected in samples from April with an average concentration of $238 \mathrm{ng} / \mathrm{L}$, and EtPB was scarcely found, with only $4 \%$ of positives in the monitoring of April (all $<$ LOQ). BuPB, CFA and CBZ were not detected in any of the samples from this reservoir. In general, not a clear trend was observed in the concentrations of these compounds as a function of the sampling date.

Concentrations of $\mathrm{MePB}$, and mainly IBU, seemed to slightly increase along the depth of the water column in most of sampling stations (Fig 1SI), which would imply that these compounds are sorbed onto the sediments (IBU, Log $\mathrm{K}_{\mathrm{ow}}$ 3,97; MePB, Log $\mathrm{K}_{\mathrm{ow}}$ 4,5) (Fatta-Kassinos et al., 2013; Vergili, 2013). In addition, humic material tends to accumulate into the bottom, which might facilitate the complexation with the contaminants (Hincapie - Upegui., 2014) that would be associated to the sediments and/or to the bottom of the water column.

We did not observe a clear trend in the spatial distribution of MePB in the different stations monitored in this reservoir, although a notable increase in concentration in the bottom samples was found in stations 7 and 8 in October 2012 (Fig 1SI), a fact that could not be easily explainable. For IBU, the trend of the concentrations was more uniform in sub-surface, photic limit zone and bottom samples. In general, concentrations in station 1, which was near the tributary Rio Chico (number 12) were a bit higher, and then decreased along stations 2 and 3 (see map shown in Figure 1). However, the possible influence of the other tributaries was not so evident in those stations that might be more affected, i.e. stations 6,4 and 10.

Additionally to samples from reservoir RG, water samples were also collected in each tributary at locations just before the entry to the reservoir (Fig 1) in order to evaluate whether they were the main source of pollution of the reservoir. Concentration data found in tributaries 12, 15, 17 and 19, in the two monitoring campaigns, are shown in Table 4.

In the tributaries, similarly to the reservoir samples, the predominant compounds were BZP, MePB and IBU, although BZP-3 was also found at notable concentrations in samples collected in April. The presence of IBU in tributary 12 (Rio Chico) in both monitoring campaigns may explain the presence of this compound in reservoir samples of station 1, located near the entry of this tributary. From sampling station 1 onwards, IBU concentrations slightly decreased along the distance (stations 2 and 3 ).

$\mathrm{BZP}$ and $\mathrm{MePB}$ were present in all tributaries, which might explain the presence of these compounds in the reservoir. Similarly to the results found in the reservoir, BZP-3 was only found in the samples collected in April 2012. Although no relevant differences were observed in general between the 
tributaries in terms of analyte concentrations, the tributary 15 was the only one where the three parabens included in this study, BuPB, EtPB and MePB, were found, with the latter being present at relatively high concentrations $(242 \mathrm{ng} / \mathrm{L})$.

\subsubsection{Reservoir La Fe (LF)}

In general, the behaviour and concentrations found in this reservoir were similar to those found in reservoir RG. The higher concentrations were commonly observed in the first monitoring, June 2012, although no significant variations were observed along the different periods of the year.

The compounds most detected in this reservoir were again BZP, MePB and IBU, although other parabens $(\mathrm{BuPB}, \mathrm{EtPB})$ were also found in several of the samples at detectable concentrations (mostly below 60 ng/L) (Table 5).

Additionally, the most important tributaries (numbers 8, 9, 10, 11; see map in Figure 2) were also monitored in October and December 2012, and February 2013 (Table 6). The PPCPs concentrations in these tributaries were lower than tributaries from the other reservoir (see Table 4), as only IBU and MePB were found at detectable concentrations (no data available for BZP). In all positives, concentrations were below $80 \mathrm{ng} / \mathrm{L}$. This fact illustrates that, at least for the compounds selected in this study, the tributaries seemed not be an important source of pollution in the reservoir.

No clear trends were observed in the spatial distribution of the compounds in this reservoir (Fig 2SI) and, as stated above, the influence of the tributaries was not perceived.

The presence of PPCPs in urban wastewater has been widely reported in the scientific literature, at concentrations that are sometimes well above $1000 \mathrm{ng} / \mathrm{L}$. High levels can be found even in effluent wastewater, as many of these compounds are not efficiently removed in WWTPs (Alidina et al., 2014; Anumol and Snyder, 2015; Carmona et al., 2014; Gracia-Lor et al., 2012b; Gros et al., 2010; Jelic et al., 2011; Lacey et al., 2008; Liu and Wong, 2013). This fact explains that a notable number of PPCPs are present in surface water, including the compounds studied in this work.

Specifically, MePB has been found in wide concentrations ranges, with average values near those reported in our work for reservoir samples (around 100 ng/L) (Carmona et al., 2014; Kasprzyk-Hordern et al., 2008; Peng et al., 2008). Ibuprofen is one of the compounds more frequently detected in surface water around the world (Fernández et al., 2010; Kasprzyk-Hordern et al., 2008; Lindholm-Lehto et al., 2016; Liu et al., 2015; Liu and Wong, 2013; Matamoros et al., 2012; Peng et al., 2008; Tran et al., 2014; Wang et al., 2010). Concentrations reported are commonly higher than those found in reservoirs RG and LF. Thus, values up to 2,700 and 1,800 ng/L have been reported for IBU in Spain and Vietnam, respectively (Fernández et al., 2010; Tran et al., 2014), which are clearly higher than in our work ( $\leq 60 \mathrm{ng} / \mathrm{L}$ ).

Less data exist on BZP levels in surface water, and most studies are focused on BZP-3 (Kim and Choi, 2014). The presence of BZP has been reported in surface water from California, with maximum concentrations of $5.1 \mathrm{ng} / \mathrm{L}$ (Alvarez et al., 2014). Although not detected in our study, BZP-3 is commonly found in surface water, at levels up to $125 \mathrm{ng} / \mathrm{L}$ (Kim and Choi, 2014). 

reservoir samples. However, their presence in surface water has been reported in several previous studies.

316 For example, CBZ has been found at low concentrations in Finland (1.2 ng/L) (Lindholm-Lehto et al., 317 2016), and at much higher concentrations in Vietnam (5,110 ng/L) (Tran et al., 2014). DIC is commonly 318 reported in surface water, at concentrations from $10 \mathrm{ng} / \mathrm{L}$, in Switzerland, to $700 \mathrm{or} 800 \mathrm{ng} / \mathrm{L}$, in China or 319 Spain (Fernández et al., 2010; Wang et al., 2010). Parabens (Carmona et al., 2014; Esteban et al., 2014; 320 Kasprzyk-Hordern et al., 2008) and CFA are usually present at low levels in fresh waters (around or 321 below $50 \mathrm{ng} / \mathrm{L}$ ) (Gros et al., 2006; Hernando et al., 2006; Kasprzyk-Hordern et al., 2008; Öllers et al., 322 2001; Wang et al., 2010).

323 Data from above show that the compounds selected in our study are commonly present in fresh water 324 from many countries around the world. In general, the levels reported in our work for reservoir water and tributaries samples are lower than reported in the majority of studies performed in other countries. However, more data and extensive monitoring programs would be necessary to confirm this fact.

\subsection{Drinking water treatment plant samples}

329 Four monitoring campaigns were carried out in two DWTPs: Los Manatiales (MA) and La Ayurá (Table 330 1SI). The DWTP of MA receives water from the reservoir RG, and the catchment is located at station 4 331 (Fig 1), while DWTP of LA receives water from reservoir LF, with the catchment being located at station 3 (Fig 2).

The results obtained for analyses of influent water (water from the reservoir collected in the catchment station) and in effluent water (treated water already used for drinking water supply) are shown in Table 7. The compounds IBU, MePB and BZP were the most frequently detected, similarly to the reservoir and tributary samples. These were present in both influent and treated water of the two drinking water treatment plants. The concentrations found in the influents were in general consistent with those of the reservoir samples, specifically from stations 4 (RG) and 3 (LF), where the catchments are located. This supports the observation that these compounds are present in the reservoir water and enter in the DWTP. In addition to the three major contaminants, BZP-3, DIC and BuPB were occasionally detected in the influent of MA, although at concentrations $<30 \mathrm{ng} / \mathrm{L}$. The first two compounds were also occasionally found in the RG reservoir samples in some monitoring campaigns, but BuPB was never found in the reservoir; a fact that needs further research for confirmation. A similar situation was observed in influent samples from LA, where in addition to the three major compounds, BZP-3 and DIC were occasionally detected although at low concentrations $(<30 \mathrm{ng} / \mathrm{L})$, while they were not detected in the LF reservoir samples.

The comparison of data from influent and effluent samples from DWTPs showed that PPCPs present in the catchment were not completely removed in the conventional treatment applied. For example, the removal efficiency for BZP, MePB and IBU was found to be between 30-60\% (BZP), 20-60\% (MePB), in agreement with previous data reported on drinking water treatment (de Jesus Gaffney et al., 2014; 
Padhye et al., 2014). Both DWTPs apply conventional treatments, based on coagulation, flocculation, sedimentation and filtration, which would be expected to efficiently remove hydrophobic compounds of high molecular weight, less soluble in water, but not necessarily emerging contaminants that are more polar in nature. For this reason, polar emerging compounds, as the majority of PPCPs, when present in water at low concentrations, would remain in the aqueous phase and would not be removed along the coagulation-flocculation process, leading to low removal efficiencies in the treatment plant (RodríguezPaniagua, 2015).

In addition, both DWTPs also apply chlorination, a process that allow to eliminate the great majority of organic compounds, although not all of them. It has been reported that the use of oxidizing agents is appropriate for removal of emerging contaminants in drinking water treatment (Huber et al., 2005), however, the kinetic of the process can be slow and other by-products (in some occasions of unknown effects on human health) can be formed (Rodríguez-Paniagua, 2015). According to our data, it seems that the low chlorine doses used in the DWTPs were not sufficient to completely remove some PPCPs. Therefore, it would be necessary to improve the treatment in order to remove trace levels of PPCPs in drinking water, for example, using higher doses of chlorine or implementing tertiary treatments, such as advanced oxidation systems, that are more efficient to this aim.

In any case, the levels found in drinking water (effluent already treated and used for drinking water supply) were always below $50 \mathrm{ng} / \mathrm{L}$, with the only exception of MePB in the sample collected in MA in September 2012 (80 ng/L) (Table 7). Although concentrations were below $0.1 \mu \mathrm{g} / \mathrm{L}$ (the reference value used by default for pesticide residues in drinking water), no sufficient data exist to assess the potential harmful effects on human health. Therefore, more research is required in the near future on this issue.

Confirmation of positive findings was based on the agreement of $\mathrm{Q} / \mathrm{q}$ ratios and chromatographic retention times between samples and reference standards (see Analytical Methodology). Similarly to the reservoir and tributary samples, QCs (drinking water samples fortified at $0.25 \mu \mathrm{g} / \mathrm{L}$ with the selected PPCPs) were analyzed in every sequence in order to test the robustness and applicability of the method.

As illustrative example, Fig 3 shows the LC-MS/MS chromatograms for an effluent sample from Manantiales DWTP, where BZP and MePB were found and their identity confirmed by Rt and ion/ratio agreement with the reference standard.

Our findings are in the line of previous data reported on occurrence of PPCPs in drinking water around the world. It is not rare to find some of these compounds in drinking water at the few $\mathrm{ng} / \mathrm{L}$ level. Specifically, the compounds selected in our work have been found in drinking waters, as summarized in a recent review (Bialk-Bielinska et al., 2016), where maximal concentrations reported for diclofenac, carbamazepine and ibuprofen are given. Thus, IBU was frequently reported in DW from USA, Japan, China, Portugal and Spain, typically at concentrations between 10-30 ng/L. DIC was also reported in DW from Japan and China at maximal concentrations of 16 and $10 \mathrm{ng} / \mathrm{L}$, respectively; and also in Spain, at average concentrations of $18 \mathrm{ng} / \mathrm{L}$ (Bialk-Bielinska et al., 2016; Carmona et al., 2014). However, it seems that this compound was not present in finished water, after disinfection (Cai et al., 2014). Contrarily to our work, where CBZ was not detected in DW, this compound was frequently found, at maximal concentrations between 2 and $5.6 \mathrm{ng} / \mathrm{L}$, in DW from Canada, Spain and USA, and between 14 and 35 
$\mathrm{ng} / \mathrm{L}$ in Portugal, Japan and China. CBZ was also found in finished water subjected to disinfection in all the five sample analysed from Beijing, China, at concentrations between 0.4 and $1.2 \mathrm{ng} / \mathrm{L}$ (Cai et al., 2014).

There are very few data on the presence of parabens in drinking water (Haman et al., 2015). In the United States, MePB was never detected in a study on drinking water sources and treated drinking water (Loraine and Pettigrove, 2006). However, in Spain MePB (17 and $40 \mathrm{ng} / \mathrm{L}$ ) was quantified in tap water (Blanco et al., 2009; Casas Ferreira et al., 2011). These two studies did not observe any EtPB, PrPB or BuPB. Another recent Spanish study (Carmona et al., 2014) demonstrated the presence of MePB (12 ng/L), PrPB $(9 \mathrm{ng} / \mathrm{L})$ and $\mathrm{BuPB}(28 \mathrm{ng} / \mathrm{L})$, but not EtPB. In our work, MePB was also found at concentrations between 21 and $80 \mathrm{ng} / \mathrm{L}$, while EtPB was not detected, and BuPB was only once at $7 \mathrm{ng} / \mathrm{L}$.

Although the presence of the UV filters benzophenones in effluent wastewater and surface water has been reported, there are very little studies on drinking water. BZP-4 was found in DW from Galicia, Spain, at maximum concentrations of $62 \mathrm{ng} / \mathrm{L}$ (Rodil et al., 2012), close to the levels reported in our work (around $40 \mathrm{ng} / \mathrm{L}$ ). Benzophenone was also reported in an early study made in the United States in drinking water at concentrations above $100 \mathrm{ng} / \mathrm{L}$ (Loraine and Pettigrove, 2006).

The regulations on PPCPs in drinking water are still insufficient around the world, and no maximum levels have been established in most countries yet. Taking as a reference the maximum level allowed for pesticides in drinking water according to the European Directive (European Union, 1998) $(0.1 \mu \mathrm{g} / \mathrm{L}$ ), the concentrations found for the PPCPs under study were lower than this value. However, it is not possible to fully evaluate the potential hazard of PPCPs at these low levels for public health due to the lack of longterm exposition risk data for these compounds. However, the application of the precautionary principle seems necessary, and measurements should be taken to efficiently remove PPCPs in the DWTPs.

The research presented in this paper can be considered as a preliminary study that reveals the occurrence of selected PPCPs in reservoirs of Medellin, and their potential presence in drinking water produced from these reservoirs. Subsequent actions will be needed in the near future, including ambitious monitoring programs where the number of compounds should be notably increased. In addition, selected metabolites/TPs should be also included in the monitoring, because most pharmaceuticals are excreted as metabolites more than as the parent compound, and can also suffer degradation/transformation processes in the aquatic environment. Therefore, the occurrence of TPs can be more frequent than that of the parent compounds (Boix et al., 2016; Ibáñez et al., 2016).

\section{Conclusions}

In this work, several PPCPs have been monitored in two important reservoirs near Medellin, as well as in the main tributaries of these reservoirs. Our data showed that some preservatives (parabens, mainly MePB), UV-filters, as BZPs and BZP-3, and the pharmaceutical IBU were present in most of the samples analysed. The presence of these compounds in the tributaries may explain their detection in the reservoir water samples, although other sources of pollution should not be discarded. 
As reservoir water is used for catchment of drinking water treatment plants, these compounds (mainly MePB, IBU and BZP) were also present in the influent of the DWTPs. Analysis of treated water showed that these compounds were not completely removed after the conventional treatments applied for drink water supply (coagulation, flocculation, sedimentation, filtration, and subsequent disinfection by chlorination). This reveals that conventional treatments, which had been designed to remove the great majority of organic matter, are not efficient enough to remove polar contaminants present at low concentrations in the influent water, as occurs for most of emerging contaminants.

The PPCPs concentrations found in drinking water were all below $80 \mathrm{ng} / \mathrm{L}$ (e.g. below $0.1 \mu \mathrm{g} / \mathrm{L}$, which is the maximum concentration allowed for pesticides - a group of contaminants subjected to strict regulation in drinking water). Insufficient information exists to assess the potential harmful effects of these low levels on human health. It seems necessary the application of the precautionary principle until more data are available to properly evaluate the risks for the population. More research is required in the near future considering a higher number of PPCPs, including the most consumed by population, because synergic effects have to be taken into account. The presence of metabolites and transformation products is another issue of concern, as many pharmaceuticals are hardly excreted as parent compound; therefore, the presence of some parent pharmaceuticals may only be the visible part of the iceberg of this complex and of current concern issue.

\section{Acknowledgements}

This work has been developed under the financial support provided by Empresa Públicas de Medellin. The authors wish to thank Marian Martinez from the GDCON research team for their help with the analysis. Carolina Aristizábal is especially grateful with Carlos Lopez, professor of University of Antioquia, for his technical advice in the development of this work. The advices and help of Professor Felix Hernandez, from University Jaume I, is greatly appreciated.

\section{SUPPLEMENTARY MATERIAL}

In this section, two figures are included, showing the distribution of IBU and MePB in reservoir RG (Figure 1SI) and in reservoir LF (Figure 2SI) water collected at three depths for different sampling stations and monitoring dates. Also three tables, 1SI: Monitoring plan for reservoirs, tributary rivers and DWTPs, 2SI: Concentrations (ng/L) found for BZP, MePB and IBU in samples from reservoir RG, 3SI: Concentrations (ng/L) found for BZP, MePB and IBU in samples from reservoir LF, are included to support the information given in the manuscript. 


\section{REFERENCES}

Alidina, M., Hoppe-Jones, C., Yoon, M., Hamadeh, A.F., Li, D., Drewes, J.E., 2014. The occurrence of emerging trace organic chemicals in wastewater effluents in Saudi Arabia. Sci. Total Environ. 478, $152-162$.

Alvarez, D. a., Maruya, K. a., Dodder, N.G., Lao, W., Furlong, E.T., Smalling, K.L., 2014. Occurrence of contaminants of emerging concern along the California coast (2009-10) using passive sampling devices. Mar Pollut Bull 81, 347-354.

Anumol, T., Snyder, S. a., 2015. Rapid analysis of trace organic compounds in water by automated online solid-phase extraction coupled to liquid chromatography-tandem mass spectrometry. Talanta 132, $77-86$.

Bade, R., Rousis, N.I., Bijlsma, L., Gracia-Lor, E., Castiglioni, S., Sancho, J. V., Hernandez, F., 2015. Screening of pharmaceuticals and illicit drugs in wastewater and surface waters of Spain and Italy by high resolution mass spectrometry using UHPLC-QTOF MS and LC-LTQ-Orbitrap MS. Anal Bional. Chem. 407, 8979-8988.

Barceló, D., Petrovic, M., 2007. Pharmaceuticals and personal care products (PPCPs) in the environment. Anal. Bioanal. Chem. 387, 1141-1142.

Bialk-Bielinska, A., Kumirska, J., Borecka, M., Caban, M., Paszkiewicz, M., Pazdro, K., Stepnowski, P., 2016. Selected analytical challenges in the determination of pharmaceuticals in drinking/marine waters and soil/sediment samples. J Pharm Biomed Anal 121, 271-296.

Blanco, E., Casais, M. del C., Mejuto, M. del C., Cela, R., 2009. Combination of off-line solid-phase extraction and on-column sample stacking for sensitive determination of parabens and $\mathrm{p}$ hydroxybenzoic acid in waters by non-aqueous capillary electrophoresis. Anal Chim Acta 647, $104-111$.

Boix, C., Ibáñez, M., Bagnati, R., Zuccato, E., Sancho, J. V., Hernández, F., Castiglioni, S., 2016. High resolution mass spectrometry to investigate omeprazole and venlafaxine metabolites in wastewater. J Hazard Mater 302, 332-340.

Boyd, G.R., Reemtsma, H., Grimm, D.A., Mitra, S., 2003. Pharmaceuticals and personal care products (PPCPs) in surface and treated waters of Louisiana, USA and Ontario, Canada. Sci Total Env. 311 , $135-149$.

Brown, L.C., Berthouex, P. Mac, 2002. Statistics for Environmental Engineers. Limit of detection., Second Edi. ed. January 29, by CRC Press.

Cai, M.-Q., Wang, R., Feng, L., Zhang, L.-Q., 2014. Determination of selected pharmaceuticals in tap water and drinking water treatment plant by high-performance liquid chromatography-triple quadrupole mass spectrometer in Beijing, China. Env. Sci Pollut Res 22, 1854-1867.

Carmona, E., Vicente, A., Picó, Y., 2014. Occurrence of acidic pharmaceuticals and personal care products in Turia River Basin: From waste to drinking water. Sci Total Env. 484, 53-63.

Casas Ferreira, A.M., Möder, M., Fernández Laespada, M.E., 2011. GC-MS determination of parabens, triclosan and methyl triclosan in water by in situ derivatisation and stir-bar sorptive extraction. Anal Bional. Chem. 399, 945-953.

Dai, G., Wang, B., Huang, J., Dong, R., Deng, S., Yu, G., 2015. Occurrence and source apportionment of pharmaceuticals and personal care products in the Beiyun River of Beijing, China. Chemosphere 119, 1033-1039.

Daughton, C., Ternes, T., 1999. Special Report: Pharmaceuticals and personal care products in the enviornment: Agents of subtle change? Env. Heal. Perspec 107, 907-938.

Daughton, C.G., 2004. Non-regulated water contaminants: Emerging research. Env. Impact Asses 24, 711-732.

de Jesus Gaffney, V., Almeida, C.M.M., Rodrigues, A., Ferreira, E., Benoliel, M.J., Cardoso, V.V., 2014. Occurrence of pharmaceuticals in a water supply system and related human health risk assessment. 
Esteban, S., Gorga, M., Petrovic, M., González-Alonso, S., Barceló, D., Valcárcel, Y., 2014. Analysis and occurrence of endocrine-disrupting compounds and estrogenic activity in the surface waters of Central Spain. Sci Total Env. 466-467, 939-951.

European Union, 1998. Council Directive 98/83/EC of 3 November 1998 on the quality of water intended for human consumption. Off. J. Eur. Communities L330, 32-54.

Farré, M. la, Pérez, S., Kantiani, L., Barceló, D., 2008. Fate and toxicity of emerging pollutants, their metabolites and transformation products in the aquatic environment. TrAC 27, 991-1007.

Fatta-Kassinos, D., Bester, K., Kümmerer, K., 2013. Mass Flows, Environmental Processes, Mitigation and Treatment Strategies "Xenobiotics in the Urban Water Cycle," Springer.

Fernández, C., González-Doncel, M., Pro, J., Carbonell, G., Tarazona, J. V., 2010. Occurrence of pharmaceutically active compounds in surface waters of the henares-jarama-tajo river system (madrid, spain) and a potential risk characterization. Sci Total Env. 408, 543-551.

Gracia-Lor, E., Martinez, M., Sancho, J. V., Peñuela, G., Hernandez, F., 2012a. Multi-class determination of personal care products and pharmaceuticals in environmental and wastewater samples by ultrahigh performance liquid-chromatography-tandem mass spectrometry. Talanta 99, 1011-1023.

Gracia-Lor, E., Sancho, J. V., Serrano, R., Hernandez, F., 2012b. Occurrence and removal of pharmaceuticals in wastewater treatment plants at the Spanish Mediterranean area of Valencia. Chemosphere 87, 453-462.

Gros, M., Petrovic, M., Barcelo, D., 2006. Development of a multi-residue analytical methodology based on liquid chromatography-tandem mass spectrometry (LC-MS/MS) for screening and trace level determination of pharmaceuticals in surface and wastewaters. Talanta 70, 678-690.

Gros, M., Petrovic, M., Ginebreda, A., Barceló, D., 2010. Removal of pharmaceuticals during wastewater treatment and environmental risk assessment using hazard indexes. Enviroment Int. 36, 15-26.

Haman, C., Dauchy, X., Rosin, C., Munoz, J.F., 2015. Occurrence, fate and behavior of parabens in aquatic environments: A review. Water Res 68, 1-11.

Hernández, F., Ibáñez, M., Botero-Coy, A.-M., Bade, R., Bustos-López, M.C., Rincón, J., Moncayo, A., Bijlsma, L., 2015. LC-QTOF MS screening of more than 1,000 licit and illicit drugs and their metabolites in wastewater and surface waters from the area of Bogotá, Colombia. Anal. Bioanal. Chem. 407, 6405-6416.

Hernando, M.D., Heath, E., Petrovic, M., Barceló, D., 2006. Trace-level determination of pharmaceutical residues by LC-MS/MS in natural and treated waters. A pilot-survey study. Anal. Bioanal. Chem. 385, 985-991.

Hincapie - Upegui., D.A., 2014. Caracterización espacio-temporal y a nivel molecular de la materia orgánica disuelta en los embalses abastecedores de agua potable de los embalses Riogrande II y La $\mathrm{Fe}$ - Antioquia, Colombia. Universidad de Antioquia.

Huber, M.M., Korhonen, S., Ternes, T.A., Von Gunten, U., 2005. Oxidation of pharmaceuticals during water treatment with chlorine dioxide. Water Res. 39, 3607-3617.

Ibáñez, M., Borova, V., Boix, C., Aalizadeh, R., Bade, R., Thomaidis, N.S., Hernández, F., 2016. UHPLC-QTOF MS screening of pharmaceuticals and their metabolites in treated wastewater samples from Athens. J Hazard Mater In press. doi:10.1016/j.jhazmat.2016.03.078

Jelic, A., Gros, M., Ginebreda, A., Cespedes-Sánchez, R., Ventura, F., Petrovic, M., Barceló, D., 2011. Occurrence, partition and removal of pharmaceuticals in sewage water and sludge during wastewater treatment. Water Res. 45, 1165-1176.

Kasprzyk-Hordern, B., Dinsdale, R.M., Guwy, A.J., 2008. The occurrence of pharmaceuticals, personal care products, endocrine disruptors and illicit drugs in surface water in South Wales, UK. Water Res. 42, 3498-3518.

Kim, S., Choi, K., 2014. Occurrences, toxicities, and ecological risks of benzophenone-3, a common 
component of organic sunscreen products: A mini-review. Env. Int 70, 143-157.

Kumar, A., Xagoraraki, I., 2010. Pharmaceuticals, personal care products and endocrine-disrupting chemicals in U.S. surface and finished drinking waters: A proposed ranking system. Sci. Total Environ. 408, 5972-5989.

Lacey, C., McMahon, G., Bones, J., Barron, L., Morrissey, A., Tobin, J.M., 2008. An LC-MS method for the determination of pharmaceutical compounds in wastewater treatment plant influent and effluent samples. Talanta 75, 1089-1097.

Lindholm-Lehto, P.C., Ahkola, H.S.J., Knuutinen, J.S., Herve, S.H., 2016. Widespread occurrence and seasonal variation of pharmaceuticals in surface waters and municipal wastewater treatment plants in central Finland. Env. Sci Pollut Res 23, 7985-7997.

Liu, J., Lu, G., Xie, Z., Zhang, Z., Li, S., Yan, Z., 2015. Occurrence, bioaccumulation and risk assessment of lipophilic pharmaceutically active compounds in the downstream rivers of sewage treatment plants. Sci Total Env. 511, 54-62.

Liu, J.-L., Wong, M.-H., 2013. Pharmaceuticals and personal care products (PPCPs): A review on environmental contamination in China. Env. int 59, 208-224.

Loraine, G., Pettigrove, M., 2006. Seasonal Variations in Concentrations of Pharmaceuticals and Personal Care Products in Drinking Water and Reclaimed Wastewater in Southern California Seasonal Variations in Concentrations of Pharmaceuticals and Personal Care Products in Drinking Water and. Env. Sci Technol 40, 687-695.

Martinez, M., Peñuela, G.A., 2013. Analysis of triclosan and 4n-nonylphenol in Colombian reservoir water by gas chromatography-mass spectrometry. Water Env. J 27, 387-395.

Martinez Bueno, M.J., Herrera, S., Munaron, D., Boillot, C., Fenet, H., Chiron, S., Gómez, E., 2016. POCIS passive samplers as a monitoring tool for pharmaceutical residues and their transformation products in marine environment. Env. Sci Pollut Res 23, 5019-5029.

Martinez-Zapata, M., 2011. Estudio de la presencia y distribución de los contaminantes emergentes Triclosán y Nonilfenol en los embalses Riogrande II, La Fe, las plantas de potabilización Manantiales, La Ayurá y su degradación a Nivel de laboratorio. Universidad de Antioquia.

Matamoros, V., Arias, C.A., Nguyen, L.X., Salvadó, V., Brix, H., 2012. Occurrence and behavior of emerging contaminants in surface water and a restored wetland. Chemosphere 88, 1083-1089.

Mendez-Arriaga, F., Esplugas, S., Giménez, J., 2010. Degradation of the emerging contaminant ibuprofen in water by photo-Fenton. Water Res. 44, 589-595.

Muñoz, I., Gomez, J.M., Molina-Díaz, A., Huijbregts, M.A.J., Fernandez-Alba, A.R., García-Calvo, E., 2008. Ranking potential impacts of priority and emerging pollutants in urban wastewater through life cycle impact assessment. Chemosphere 74, 37-44.

Öllers, S., Singer, H.P., Fässler, P., Müller, S.R., 2001. Simultaneous quantification of neutral and acidic pharmaceuticals and pesticides at the low-ng/l level in surface and waste water. J Chromatogr. A 911, 225-234.

Padhye, L.P., Yao, H., Kung'u, F.T., Huang, C.H., 2014. Year-long evaluation on the occurrence and fate ofpharmaceuticals, personal care products, andendocrine disrupting chemicals in an urban drinking water treatment plant. Water Res. 51, 266-276.

Peng, X., Yu, Y., Tang, C., Tan, J., Huang, Q., Wang, Z., 2008. Occurrence of steroid estrogens, endocrine-disrupting phenols, and acid pharmaceutical residues in urban riverine water of the Pearl River Delta, South China. Sci Total Env. 397, 158-166.

Rodil, R., Quintana, J.B., Concha-Graña, E., López-Mahía, P., Muniategui-Lorenzo, S., Prada-Rodríguez, D., 2012. Emerging pollutants in sewage, surface and drinking water in Galicia (NW Spain). Chemosphere 86, 1040-1049.

Rodríguez-Paniagua, E., 2015. Removal of emerging contaminants in waters by means of physicochemical procedures. Universidad de Extremadura. 
Saravanan, M., Karthika, S., Malarvizhi, A., Ramesh, M., 2011. Ecotoxicological impacts of clofibric acid and diclofenac in common carp (Cyprinus carpio) fingerlings: Hematological, biochemical, ionoregulatory and enzymological responses. J Hazard Mater 195, 188-194.

Scheurell, M., Franke, S., Shah, R.M., Hühnerfuss, H., 2009. Occurrence of diclofenac and its metabolites in surface water and effluent samples from Karachi, Pakistan. Chemosphere 77, 870-876.

Sodré, F., Locatelli, M.A., Jardim, W.F., 2010. Occurrence of emerging contaminants in Brazilian drinking waters: A sewage-to-tap issue. Water Air Soil Poll 206, 57-67.

Sun, S.P., Zeng, X., Lemley, A.T., 2013. Kinetics and mechanism of carbamazepine degradation by a modified Fenton-like reaction with ferric-nitrilotriacetate complexes. J Hazard Mater 252-253, 155-165.

Tran, N.H., Urase, T., Ta, T.T., 2014. A preliminary study on the occurrence of pharmaceutically active compounds in hospital wastewater and surface water in Hanoi, Vietnam. Clean - Soil, Air, Water 42, 267-275.

Uhlmann, D., Paul, L., Hupfer, M., Fischer, R., 2011. "Lakes and Reservoirs" in Treatise on Water Science. doi:10.1016/B978-0-444-53199-5.00034-8

Vergili, I., 2013. Application of nanofiltration for the removal of carbamazepine, diclofenac and ibuprofen from drinking water sources. J Env. Manag. 127, 177-187.

Vulliet, E., Cren-Olivé, C., Grenier-Loustalot, M.F., 2011. Occurrence of pharmaceuticals and hormones in drinking water treated from surface waters. Env. Chem Lett 9, 103-114.

Wang, J., Leung, D., Chow, W., 2010. Applications of LC/ESI-MS/MS and UHPLC QqTOF MS for the determination of 148 pesticides in berries. J Agri . Food Chem 58, 5904-25.

Yang, G., Fan, M., Zhang, G., 2014. Emerging contaminants in surface waters in China-a short review. Env. Res Lett 9, 74018.

Zeng, E., 2015. Persistent Organic Pollutants (POPs): Analytical Techniques, Environmental Fate and Biological Effects. 
Table 1. MS conditions for the LC-MS/MS measurement of the compounds under study.

\begin{tabular}{|c|c|l|c|c|c|c|}
\hline Compound & $\begin{array}{c}\text { ESI } \\
\text { mode }\end{array}$ & $\begin{array}{c}\text { Quantification } \\
\text { transition (Q) }\end{array}$ & $\begin{array}{c}\text { Cone } \\
\text { Voltage (V) }\end{array}$ & $\begin{array}{c}\text { Confirmation } \\
\text { transition (q) }\end{array}$ & $\begin{array}{c}\text { Collision } \\
\text { Energy (ev) }\end{array}$ & $\mathbf{Q}_{\mathbf{q}} \mathbf{q}_{\mathbf{1}} *$ \\
\hline $\begin{array}{c}\text { Benzophenone } \\
\text { (BZP) }\end{array}$ & + & $182.9>104.9$ & 34 & $182.9>76.9$ & 14 & $3.39(3.5)$ \\
\hline $\begin{array}{c}\text { Benzophenone-3 } \\
\text { (BZP-3) }\end{array}$ & + & $228.9>150.9$ & 42 & $228.9>104.9$ & 18 & $1.18(5.1)$ \\
\hline $\begin{array}{c}\text { Butylparaben } \\
\text { (BuPB) }\end{array}$ & - & $193.1>92.0$ & 42 & $192.9>136.1$ & 24 & $2.15(3.6)$ \\
\hline $\begin{array}{c}\text { Carbamazepine } \\
\text { (CBZ) }\end{array}$ & + & $237.1>194.1$ & 25 & $237.1>165.2$ & 20 & $42.6(4.2)$ \\
\hline $\begin{array}{c}\text { Clofibric Acid } \\
\text { (CFA) }\end{array}$ & - & $215.2>129.0$ & 20 & $213.7>127.0$ & 15 & $5.03(7.0)$ \\
\hline $\begin{array}{c}\text { Diclofenac } \\
\text { (DIC) }\end{array}$ & - & $294.1>250.0$ & 20 & $295.8>252.0$ & 10 & $1.33(3.2)$ \\
\hline $\begin{array}{c}\text { Ethylparaben } \\
\text { (EtPB) }\end{array}$ & - & $165.1>92.0$ & 36 & $164.8>136.7$ & 20 & $1.78(9.5)$ \\
\hline $\begin{array}{c}\text { Ibuprofen } \\
\text { (IBU) }\end{array}$ & - & $205.1>161.1$ & 20 & - & 5 & - \\
\hline $\begin{array}{c}\text { Methylparaben } \\
\text { (MePB) }\end{array}$ & - & $151.0>92.0$ & 34 & $150.8>135.9$ & 20 & $1.67(4.3)$ \\
\hline Ibuprofen-D3 & - & $208.1>164.0$ & 20 & - & 10 & - \\
\hline Ethylparaben-D4 & - & $169.2>96.1$ & 30 & - & 25 & - \\
\hline
\end{tabular}

635

636

$637 *$ Average ion intensity ratios for calibration standards (7 calibration points), and relative standard

638 deviation in brackets

639

640

641

642

643

644

645

646

647

648

649

650

651 
Table 2. Analytical characteristics of the method: average recovery (\%) and precision (expressed as \% RSD, in brackets) for three fortification levels (five replicates each). Limits of quantification of the method (LOQ)

\begin{tabular}{|c|c|c|c|c|c|c|c|c|c|c|c|}
\hline \multirow[b]{2}{*}{ Compound } & \multirow[b]{2}{*}{$\mathbf{t}_{\mathbf{R}}$} & \multirow[b]{2}{*}{$\begin{array}{c}\text { LOQ } \\
(\mathbf{n g} / \mathbf{L})\end{array}$} & \multicolumn{3}{|c|}{ Reservoir $L F$} & \multicolumn{3}{|c|}{ Reservoir RG } & \multicolumn{3}{|c|}{ Ultra Pure water } \\
\hline & & & $\begin{array}{c}0.05 \\
\mu \mathrm{g} / \mathrm{L}\end{array}$ & $\begin{array}{c}0.25 \\
\mu g / L\end{array}$ & $\begin{array}{c}0.45 \\
\mu \mathrm{g} / \mathrm{L}\end{array}$ & $\begin{array}{c}0.05 \\
\mu \mathrm{g} / \mathrm{L}\end{array}$ & $\begin{array}{l}0.25 \\
\mu g / L\end{array}$ & $\begin{array}{c}0.45 \\
\mu \mathrm{g} / \mathrm{L}\end{array}$ & $\begin{array}{c}0.05 \\
\mu \mathrm{g} / \mathrm{L}\end{array}$ & $\begin{array}{c}0.25 \\
\mu \mathrm{g} / \mathrm{L}\end{array}$ & $\begin{array}{c}0.45 \\
\mu \mathrm{g} / \mathrm{L}\end{array}$ \\
\hline BZP & 7.47 & 2.8 & $96(1)$ & $76(9)$ & $75(7)$ & $88(4)$ & $71(10$ & $73(8)$ & $69(6)$ & $75(17)$ & $80(11)$ \\
\hline BZP-3 & 8.24 & 2.3 & $115(17)$ & $78(10)$ & $90(7)$ & $97(12)$ & $85(8)$ & $88(10)$ & $90(2)$ & $78(5)$ & $76(2)$ \\
\hline BuPB & 7.54 & 7.8 & $97(8)$ & $79(4)$ & $85(2)$ & $84(5)$ & $88(3)$ & $82(10)$ & $103(5)$ & $95(4)$ & $106(4)$ \\
\hline CBZ & 6.22 & 4.6 & $98(9)$ & $84(4)$ & $89(1)$ & $91(8)$ & $89(2)$ & $85(8)$ & $78(26)$ & $89(5)$ & $84(2)$ \\
\hline CFA & 7.22 & 10.3 & $91(14)$ & $80(7)$ & $81(2)$ & $65(9)$ & $69(5)$ & $59(8)$ & $82(8)$ & $97(8)$ & $90(5)$ \\
\hline DIC & 8.57 & 9.6 & $90(8)$ & $83(5)$ & $89(3)$ & $86(7)$ & $87(2)$ & $84(10)$ & $104(9)$ & $93(6)$ & $104(4)$ \\
\hline EtPB & 5.64 & 7.6 & $87(10)$ & $71(10)$ & $79(2)$ & $82(6)$ & $82(3)$ & $78(8)$ & $99(3)$ & $95(7)$ & $10684)$ \\
\hline IBU & 8.77 & 6.8 & $100(15)$ & $84(11)$ & $99(6)$ & $87(17)$ & $88(6)$ & $89(10)$ & $90(19)$ & $108(16)$ & $108(7)$ \\
\hline MePB & 4.46 & 4.2 & $91(10)$ & $89(4)$ & $87(2)$ & $87(9)$ & $90(3)$ & $85(10)$ & $117(7)$ & $104(9)$ & $107(3)$ \\
\hline
\end{tabular}




\begin{tabular}{|c|c|c|c|c|c|c|c|c|c|c|}
\hline & \multicolumn{2}{|c|}{$04 / 2012$} & \multicolumn{2}{|c|}{$09 / 2012$} & \multicolumn{2}{|c|}{$10 / 2012$} & \multicolumn{2}{|c|}{$11 / 2012$} & \multicolumn{2}{|c|}{$02 / 2013$} \\
\hline & \%Positives & Conc ng/L ${ }^{(1)}$ & \%Positives & Conc ng/L & \%Positives & Conc ng/L & \%Positives & Conc ng/L & \%Positives & Conc ng/L \\
\hline BZP & 100 & $9-100(62)$ & 62 & $8-243(110)$ & 53 & $84-385(253)^{(2)}$ & n.a. ${ }^{(3)}$ & n.a & n.a. & n.a \\
\hline BZP-3 & 96 & $30-502(238)$ & 0 & & 0 & & 0 & & 0 & \\
\hline BuPB & 0 & & 0 & & 0 & & 0 & & 0 & \\
\hline CBZ & 0 & & 0 & & 0 & & 0 & & 0 & \\
\hline CFA & 0 & & 0 & & 0 & & 0 & & 0 & \\
\hline DIC & 11 & $<\mathrm{LOQ}^{(4)}$ & 0 & & 0 & & 3 & $<\mathrm{LOQ}$ & 0 & \\
\hline EtPB & 4 & $<\mathrm{LOQ}$ & 0 & & 0 & & 0 & & 0 & \\
\hline IBU & 89 & $7-19(11)$ & 63 & $5-34(10)$ & 57 & $10-25(15)$ & 100 & $7-62(17)$ & 100 & $7-58(16)$ \\
\hline МePB & 100 & $0-122(38)$ & 87 & $5-46(22)$ & 97 & $5-425(63)$ & 87 & $6-39(32)$ & 100 & $22-265(81)$ \\
\hline
\end{tabular}

(1) Range of concentrations and average (in brackets) for the positive samples

(2) Data only available for 6 out of 10 sampling stations included in the monitoring. The percentage of positives and average value correspond to the samples of those 6 sampling stations (Table 2SI for more detailed information)

(3) n.a: data not available

(4) L LOQ: detected, concentration lower than the LOQ 


\begin{tabular}{|c|c|c|c|c|c|c|c|c|c|c|}
\hline & \multicolumn{5}{|c|}{ April 2012} & \multicolumn{5}{|c|}{ November 2012} \\
\hline & E12 & E15 & E17 & E19 & $\begin{array}{l}\mathrm{QC}^{(1)} \\
\text { Rec } \\
(\%)\end{array}$ & E12 & E15 & E17 & E19 & $\begin{array}{c}\mathrm{QC} \\
\operatorname{Rec}(\%)\end{array}$ \\
\hline BZP & 13 & 48 & 54 & 25 & 105 & n.a. ${ }^{(2)}$ & n.a. & n.a. & n.a. & n.a. \\
\hline BZP-3 & 98 & 66 & 162 & - & 81 & - & - & - & - & 90 \\
\hline BuPB & $-(3)$ & $<\mathrm{LOQ}^{(4)}$ & - & - & 94 & - & - & - & - & 78 \\
\hline $\mathrm{CBZ}$ & - & - & - & - & 90 & - & - & - & - & 71 \\
\hline CFA & - & - & - & - & 87 & - & - & - & - & 87 \\
\hline DIC & - & - & - & - & 108 & - & - & - & - & 97 \\
\hline EtPB & - & 29 & - & $<\mathrm{LOQ}$ & 98 & - & - & - & - & 91 \\
\hline IBU & 32 & - & $<\mathrm{LOQ}$ & $<\mathrm{LOQ}$ & 94 & 9 & - & $<\mathrm{LOQ}$ & 12 & 94 \\
\hline МePB & $<\mathrm{LOQ}$ & 242 & 10 & 17 & 99 & 29 & 23 & 14 & 58 & 95 \\
\hline
\end{tabular}

677

678 (1) QC: Quality control. Rec (\%): \% recovery

(2) n.a.: data not available

(3) -: not detected

(4) LLOQ: detected, concentration lower than the LOQ

683

684

685

686

687

688

689

690

691

692

693

694

695

696

697 


\begin{tabular}{|c|c|c|c|c|c|c|c|c|c|c|}
\hline & \multicolumn{2}{|c|}{$06 / 2012$} & \multicolumn{2}{|c|}{$09 / 2012$} & \multicolumn{2}{|c|}{$10 / 2012$} & \multicolumn{2}{|c|}{$12 / 2012$} & \multicolumn{2}{|c|}{$02 / 2013$} \\
\hline & $\%$ Positives & Conc ng/L ${ }^{(1)}$ & $\%$ Positives & Conc ng/L & $\%$ Positives & Conc ng/L & $\%$ Positives & Conc ng/L & \%Positives & Conc ng/L \\
\hline BZP & 55 & $5-143(57)$ & 80 & $9-102(40)$ & 20 & $16-54(34)$ & n.a. ${ }^{(2)}$ & n.a. & n.a. & n.a \\
\hline BZP-3 & 0 & & 0 & & 0 & & 0 & & 0 & \\
\hline BuPB & 10 & $8-16(12)$ & 5 & 11 & 0 & & 5 & $<\mathrm{LOQ}^{(3)}$ & 10 & 18 \\
\hline CBZ & 0 & & 0 & & 0 & & 0 & & 0 & \\
\hline CFA & 0 & & 0 & & 0 & & 0 & & 0 & \\
\hline DIC & 0 & & 0 & & 0 & & 0 & & 0 & \\
\hline EtPB & 55 & $8-50(30)$ & 0 & & 5 & 8 & 5 & 59 & 10 & 18 \\
\hline IBU & 100 & $7-39(12)$ & 95 & $7-15(11)$ & 85 & 8-16 (11) & 90 & $7-10(8)$ & 100 & $7-25(12)$ \\
\hline МePB & 100 & $21-276(84)$ & 15 & $11(11)$ & 100 & $3-57(16)$ & 40 & $6-49$ (19) & 100 & $8-113(29)$ \\
\hline
\end{tabular}

702

(1) Range of concentrations and average (in brackets) for the positive samples (Table 3SI for more detailed information)

(2) n.a: data not available

(3) < LOQ: detected, concentration lower than the LOQ. 
Table 6. Concentrations $(\mathrm{ng} / \mathrm{L})$ of selected compounds in tributaries of reservoir $\mathrm{LF}$

\begin{tabular}{|c|c|c|c|c|c|c|c|c|c|c|c|c|c|c|c|}
\hline & \multicolumn{5}{|c|}{ October 2012} & \multicolumn{5}{|c|}{ December 2012} & \multicolumn{5}{|c|}{ February 2013} \\
\hline & E8 & E9 & E10 & E11 & $\begin{array}{c}\mathrm{QC}^{(1)} \\
\operatorname{Rec} \%\end{array}$ & E8 & E9 & E10 & E11 & $\begin{array}{c}\mathrm{QC} \\
\operatorname{Rec} \%\end{array}$ & E8 & E9 & E10 & E11 & $\begin{array}{c}\text { QC } \\
\text { Rec \% }\end{array}$ \\
\hline BZP & 71 & $-^{-(3)}$ & 67 & - & 78 & n.a. ${ }^{(2)}$ & n.a & n.a & n.a & n.a. & n.a. & n.a & n.a & n.a & n.a. \\
\hline BZP-3 & - & - & - & - & 85 & - & - & - & - & 75 & - & - & - & - & 88 \\
\hline BuPB & - & - & - & - & 114 & - & - & - & - & 88 & - & - & - & - & 79 \\
\hline CBZ & - & - & - & - & 102 & - & - & - & - & 77 & - & - & - & - & 91 \\
\hline CFA & - & - & - & - & 112 & - & - & - & - & 94 & - & - & - & - & 109 \\
\hline DIC & - & - & - & - & 84 & - & - & - & - & 114 & - & - & - & - & 94 \\
\hline EtPB & - & - & - & - & 87 & - & - & - & - & 81 & - & $<\mathrm{LOQ}$ & - & - & 79 \\
\hline IBU & 10 & - & $<\mathrm{LOQ}^{(4)}$ & $<\mathrm{LOQ}$ & 92 & $<\mathrm{LOQ}$ & - & $<\mathrm{LOQ}$ & $<\mathrm{LOQ}$ & 94 & 20 & - & - & 8 & 84 \\
\hline МePB & 5 & 6 & 6 & - & 104 & 10 & 14 & 17 & 13 & 112 & 24 & 57 & 25 & 34 & 110 \\
\hline
\end{tabular}

(1) QC: Quality control. Rec (\%): \% recovery

(2) n.a.: data not available

(3) -: not detected

(4) <LOQ: detected, concentration lower than the LOQ 


\begin{tabular}{|c|c|c|c|c|c|c|c|c|c|c|}
\hline \multicolumn{11}{|c|}{ Manantiales (MA) } \\
\hline & & BZP & BZP3 & BuPB & CBZ & CFA & DIC & EtPB & IBU & МеРВ \\
\hline \multirow{2}{*}{ September/12 } & Influent & 101 & 30 & 12 & $-^{(1)}$ & - & - & - & 16 & 140 \\
\hline & Effluent & 46 & 29 & 7 & - & - & - & - & $<\mathrm{LOQ}^{(2)}$ & 80 \\
\hline \multicolumn{2}{|l|}{ QC (\%Rec) ${ }^{(3)}$} & 114 & 80 & 80 & 91 & 97 & 103 & 99 & 115 & 106 \\
\hline \multirow{2}{*}{ October/12 } & Influent & 103 & 11 & - & - & - & - & - & 14 & 27 \\
\hline & Effluent & 33 & 7 & - & - & - & - & - & 14 & 21 \\
\hline \multicolumn{2}{|l|}{ QC (\%Rec) } & 73 & 108 & 67 & 74 & 119 & 90 & 120 & 110 & 127 \\
\hline \multirow{2}{*}{ November/12 } & Influent & n.a $a^{(4) .}$ & - & - & - & - & - & - & 15 & 69 \\
\hline & Effluent & n.a. & - & - & - & - & - & - & 8 & 29 \\
\hline \multicolumn{2}{|l|}{ QC (\%Rec) } & n.a. & n.a. & 87 & 94 & 124 & 122 & 119 & 110 & 114 \\
\hline \multirow{2}{*}{ February/13 } & Influent & n.a. & - & - & - & - & 23 & - & 26 & 27 \\
\hline & Effluent & n.a. & - & - & - & - & 22 & - & 21 & 27 \\
\hline \multicolumn{2}{|l|}{ QC (\%Rec) } & n.a. & n.a. & 70 & 97 & 115 & 102 & 87 & 123 & 95 \\
\hline
\end{tabular}

\begin{tabular}{|c|c|c|c|c|c|c|c|c|c|c|}
\hline \multicolumn{11}{|c|}{ La Ayurá (LA) } \\
\hline & & BZP & BZP3 & BuPB & CBZ & CFA & DIC & EtPB & IBU & МePB \\
\hline \multirow{2}{*}{ September/12 } & Influent & 32 & 30 & - & - & - & 16 & - & 14 & 32 \\
\hline & Effluent & 30 & 24 & - & - & - & $<\mathrm{LOQ}$ & - & 14 & 33 \\
\hline \multicolumn{2}{|l|}{ QC (\%Rec) } & 114 & 80 & 80 & 91 & 97 & 103 & 99 & 115 & 106 \\
\hline \multirow{2}{*}{ October/12 } & Influent & 41 & 14 & - & - & - & 12 & - & 15 & 44 \\
\hline & Effluent & 40 & 7 & - & - & - & - & - & 12 & 35 \\
\hline \multicolumn{2}{|l|}{ QC (\%Rec) } & 73 & 108 & 67 & 74 & 119 & 90 & 120 & 110 & 127 \\
\hline \multirow{2}{*}{ December/12 } & Influent & n.a. & - & - & - & - & - & - & 11 & 34 \\
\hline & Effluent & n.a. & - & - & - & - & - & - & 12 & 34 \\
\hline \multicolumn{2}{|l|}{ QC (\%Rec) } & n.a. & n.a. & 87 & 94 & 124 & 122 & 119 & 110 & 114 \\
\hline \multirow{2}{*}{ February/13 } & Influent & n.a. & - & - & - & - & - & - & 22 & 26 \\
\hline & Effluent & n.a. & - & - & - & - & - & - & 24 & 26 \\
\hline \multicolumn{2}{|l|}{ QC (\%Rec) } & n.a. & n.a. & 70 & 97 & 115 & 102 & 87 & 123 & 95 \\
\hline
\end{tabular}


Fig 1. Sampling sites at the reservoir RG. Numbers 12, 15, 17 and 19 correspond to tributaries Fig 2. Sampling sites at the reservoir LF. Numbers 8, 9, 10 and 11 correspond to tributaries

741

742

743

744

745

746

747

748

749

750

751

752

753

754

755

756

757

758

759

760

761

762

763

764

765

766

767

768

769

770

771

772

773

774

Fig 3. LC-MS/MS chromatograms for the efluent water sample of the DWTP of Manantiales, collected in September 2012, showing positive findings of BZP (A) and MePB (B). Q/q ratios and deviations with respect to the reference standard are shown.

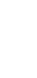

7

0

2

4

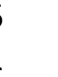

757

9

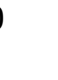

2

\section{4}

6

67

8

70

